Article

\title{
Temporal Distribution Characteristics of Alpine Precipitation and Their Vertical Differentiation: A Case Study from the Upper Shule River
}

\author{
Qingfeng $\mathrm{Li}^{1,2}$ and Guojing Yang ${ }^{1, *}$ \\ 1 State Key Laboratory of Cryospheric Sciences/Division of Hydrology Water-Land Resources in Cold and \\ Arid Regions, Cold and Arid Regions Environmental and Engineering Research Institute, \\ Chinese Academy of Science, Lanzhou 730000, China; liqingfeng83@163.com \\ 2 University of Chinese Academy of Sciences, Beijing 100049, China \\ * Correspondence: yangguojing@lzb.ac.cn; Tel.: +86-931-496-7150
}

Academic Editor: Xiangzheng Deng

Received: 27 January 2017; Accepted: 17 April 2017; Published: 19 April 2017

\begin{abstract}
Alpine precipitation is an important component of the mountain hydrological cycle and may also be a determinant of water resources in inland river basins. In this study, based on field observation data of the upper Shule River and daily precipitation records of the Tuole weather station during 2009-2015, temporal distribution characteristics of alpine precipitation and their vertical differentiation were evaluated mainly using percentages of precipitation anomalies $(\mathrm{Pa})$, coefficient of variation $(\mathrm{Cv})$, precipitation concentration degree $(P C D)$ and concentration period $(P C P)$. The results indicated that the inter-annual variability of annual precipitation was generally small, with a $P a$ that was only somewhat larger in low altitude zones for individual years; the inter-annual fluctuation of monthly precipitation increased noticeably, but the $\mathrm{Cv}$ and precipitation can be described as a power function. Annual distribution was basically consistent; more than $85.6 \%$ of precipitation was concentrated during the period from May to September; PCD ranged between 0.71 and 0.83 while the PCP was located within the 37 th-41st pentads. Diurnal variation of precipitation was defined, mainly occurring from 1500 to 0100 Local Standard Time, and displayed a vertical change that was dominated by precipitation intensity or precipitation frequency. The temporal distribution of alpine precipitation has a noticeable vertical differentiation, and this is likely to originate from the diversity of precipitation mechanisms in mountainous terrain areas.
\end{abstract}

Keywords: inland river; water resources management; alpine precipitation; inter-annual fluctuation; annual distribution; diurnal variation; vertical differentiation

\section{Introduction}

In the context of global warming, the hydrological cycle is undergoing many changes [1-4], and it profoundly affects the function and stability of the terrestrial ecosystem $[5,6]$. These transitions are particularly prominent in the arid and semi-arid regions $[7,8]$, thereby exacerbating water scarcity in inland river basins [9]. In order to ensure the sustainable development of social-economy and ecosystem health in the basin, it is necessary to objectively grasp the influence level and mechanism of climate change on hydrological elements [10]. However, in the upstream or source areas, which have the most abundant water resources, related research is still noticeably insufficient owing to harsh natural conditions and the complexity of geographical features found in alpine mountainous terrain areas [11,12]. Precipitation as a key input element is often difficult to ascertain owing to a scarcity of stations as well as intense variability [13-15], and this is the bottleneck restricting the development of meteorological and hydrological research in these regions. For nearly a dozen years, the applicability 
of remote sensing data and interpolation methods has been widely discussed and has effectively revealed the contours of precipitation in the Qinghai-Tibetan Plateau and mountainous areas $[16,17]$. Nevertheless, the error rate is generally high and combined with a scale that is too large [18], meaning that it is unable to meet the demand for quantitative analysis in the short term. At this stage, field observation is still the solid choice for expanding the knowledge on precipitation in areas where there is an information shortage. The clear understanding of local precipitation features in the Tanggula Mountains, Qilian Mountains, etc. is derived from the measured data in rare field observations [19], but representation is often greatly reduced because the observation time of the series is relatively shorter. Thus, in the alpine zone where data are generally scarce, it is worth deliberating whether the precipitation characteristics have been objectively measured. The level and mechanisms of climate change impact on the hydrologic cycle and the countermeasures against water scarcity in inland river basins also need to be further explored. Long-term observation is an important driving force for progressive answers to these scientific questions.

The Shule River originating from the western part of the Qilian Mountains on the northeastern margin of the Qinghai-Tibetan Plateau is the second largest inland river system in the Hexi Corridor of China. The major upper part of the basin lies in alpine mountains, and precipitation, which is more abundant, plays a decisive role in the basin water resources. In recent decades, the hydro-meteorological characteristics of the Shule River basin and its surroundings have been undergoing significant change, and a series of problems related to ecosystem degradation and water use efficiency have become increasingly prominent $[20,21]$. Therefore, it is necessary to construct an integrative water management system at the catchment scale for the Hexi inland region [22]. Until now, however, discussion on the precipitation of the upper Shule River has relied only on data from the Tuole station, which is the nearest national weather station, as measured results from the alpine zone have not yet been reported. Therefore, a high degree of uncertainty still exists, and any conclusions are controversial. For these reasons, based on field observation data from the upper Shule River ( $3400 \mathrm{~m}-4200 \mathrm{~m}$ ) and daily precipitation of Tuole station during 2009-2015, the distribution characteristics of alpine precipitation in the main time scales as well as their vertical differentiation were evaluated in this paper. Based on a comprehensive literature review, it is believed that the basic features of precipitation in the upper reaches of the Shule River are unexplored. Consequently, the basic features of precipitation in the upper reaches of the Shule River as well as discussions about the characteristics of alpine precipitation are synthesized in this study. The results may provide theoretical support or new thinking about the subsequent scientific research on the hydrological cycle and water resource management in mountainous regions as well as inland river basins.

\section{Materials and Methods}

\subsection{Site Description}

The study area falls within the upper reaches of the Shule River, which is located between $96.2-99.0^{\circ} \mathrm{E}$ and $38.2-40.0^{\circ} \mathrm{N}$ (Figure 1). Vegetation coverage is generally $40 \%-80 \%$, and the representative plants are Kobresiapygmaea, Stipapurpurea, Carexmoorcroftii and Kobresiatibetica. This region is mainly controlled by westerly winds and belongs to a continental arid desert climate. The mean annual air temperature is generally $-4{ }^{\circ} \mathrm{C}$, the average air temperature of the hottest month (July) and the coldest month (January) is $7.5^{\circ} \mathrm{C}$ and $-17.5^{\circ} \mathrm{C}$, respectively. The main range of annual precipitation is from 200 to $400 \mathrm{~mm}$, and this is mostly concentrated in the period from May to September. At present, there is no national weather station in the study area; the Tuole station $(3367 \mathrm{~m})$ outside the basin is relatively close (Figure 1). 


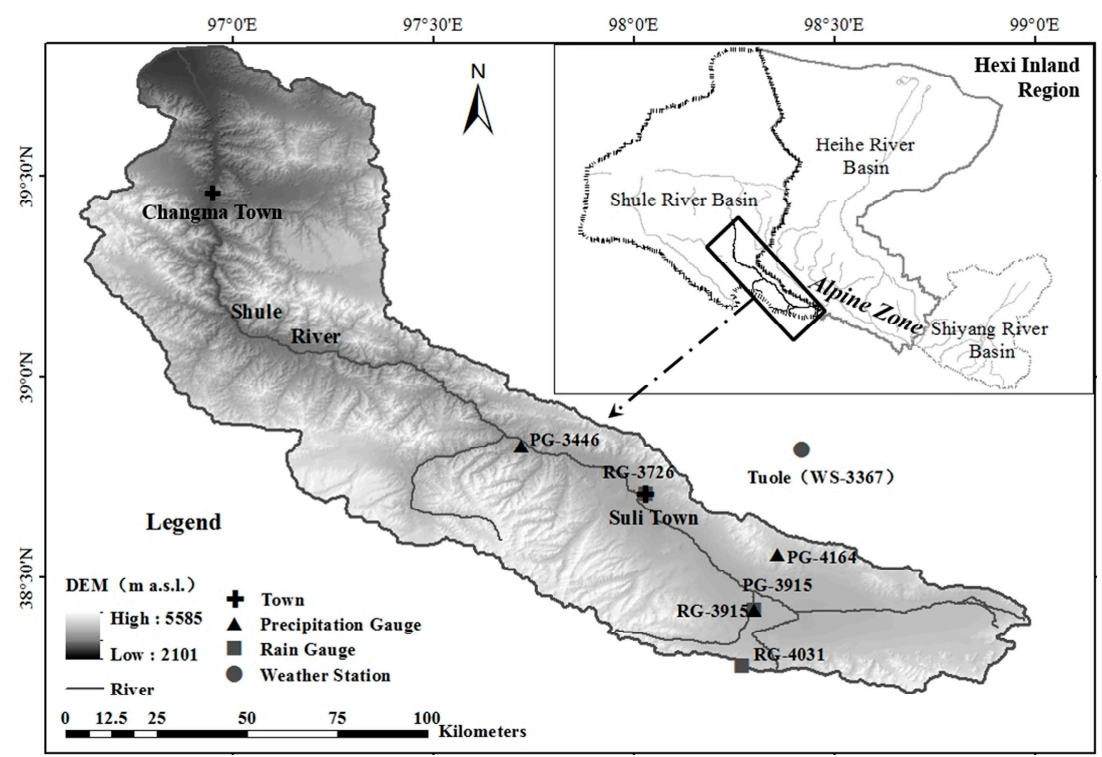

Figure 1. Precipitation observing sites in the upper reaches of the Shule River.

\subsection{Date Acquisition}

The daily precipitation of Tuole weather station (WS-3367) was downloaded from the China Meteorological Data Network (http://data.cma.cn). In-situ observed data were obtained from Shule River Field Observational Stations, Chinese Academy of Science (Figure 1 and Table 1), and all of the above raw observations were in sequences of $10 \mathrm{~min}$. The meteorological stations (PG-4164-PG-3446) measured precipitation data using the Geonor T-200B weighing gauge (sensitivity $0.1 \mathrm{~mm}$ ), which has been running since July 2008. Hydrologic stations (RG-4031-RG-3726) were established in April 2012, and precipitation records were mainly derived from tipping-bucket rain gauges (sensitivity $0.1 \mathrm{~mm}$ ), between May and September. Meanwhile, supplemented by manually read Chinese Standard Precipitation Gauges, precipitation type, start and end time and other related information was also recorded individually. To decrease the loss from wind and evaporation, a wind-proof ring was installed, and antifreeze and oil were added to the reservoir of the Geonor T-200B weighing gauge.

In view of the fact that hydrological stations (RG-4031-RG-3726) are unable to provide precipitation data other than in the rainy season, the results of inter-annual fluctuations and annual distribution were assessed using data from meteorological stations (PG-4164-PG-3446) and the Tuole weather station (WS-3367). Similarly, due to lack of data on an hourly scale, analysis of diurnal variation of data from the Tuole weather station could not carried out. In addition, in order to avoid disturbance of snowfall measurement error and other uncontrollable factors, the data from the meteorological stations have not been used for diurnal variation of precipitation.

Table 1. Details of geographical coordinates and precipitation data for observation sites in the field.

\begin{tabular}{cccccc}
\hline Site & Longitude $\left({ }^{\circ} \mathbf{E}\right)$ & Latitude $\left({ }^{\circ} \mathbf{N}\right)$ & Altitude $(\mathbf{m})$ & Record Period & Years \\
\hline PG-4164 & 98.36 & 38.56 & 4164 & & \\
PG-3915 & 98.31 & 38.42 & 3915 & Whole Year & $2009-2015$ \\
PG-3446 & 97.72 & 38.84 & 3446 & & \\
\hline RG-4031 & 98.26 & 38.30 & 4031 & & \\
RG-3915 & 98.31 & 38.42 & 3915 & Rain Season & $2012-2015$ \\
RG-3726 & 98.03 & 38.70 & 3726 & & \\
\hline
\end{tabular}




\subsection{Methods}

The percentages of precipitation anomalies $(\mathrm{Pa})$, which is an extension of the concept of anomaly, are the percentages of the difference between the precipitation for a certain study period and the annual mean value accounting for the annual mean precipitation in the same period. The calculation is shown in Equation (1).

$$
P a=\frac{P-\bar{P}}{\bar{P}} \times 100 \%
$$

where $\mathrm{Pa}$ is the percentage of precipitation anomalies. $P$ represents the precipitation of a certain study period, and $\bar{P}$ represents the annual mean precipitation in the same period. According to "The short-term climate prediction quality grading inspection approach" implemented in 2010 by the China Meteorological Administration, this study classifies $P a$ as higher $(\geq 20 \%)$, lower $(\leq-20 \%)$, and normal at three levels.

The precipitation concentration degree $(P C D)$ and the precipitation concentration period $(P C P)$ are two standard statistical parameters based on vector analysis, which can be defined to describe the temporal distribution pattern of precipitation. The PCD can reflect the precipitation concentration level during certain periods in a year. The $P C P$, as the azimuth of a composite vector, indicates when the maximum precipitation occurs. They can be defined as below:

$$
\begin{aligned}
P C D_{i} & =\sqrt{R_{x i}{ }^{2}+R_{y i}{ }^{2}} / R_{i}, \\
P C P_{i} & =\arctan \left(R_{x i} / R_{y i}\right), \\
R_{x i} & =\sum_{j=1}^{N} r_{i j} \times \sin \theta_{j}, \\
R_{y i} & =\sum_{j=1}^{N} r_{i j} \times \cos \theta_{j} .
\end{aligned}
$$

where $i$ is the year $(i=2009,2010, \ldots, 2015)$, and $R_{i}$ stands for the total precipitation of the research period in the $i$ th year. $j$ is the day (pentad or month) of year in the research period. $\theta_{j}$ represents the corresponding azimuth angle of the $j$ th day (pentad or month), while the whole research period can be seen as $360^{\circ}$. $r_{i j}$ denotes the precipitation of the $j$ th day (pentad or month) in the $i$ th year. $P C D_{i}$ is the precipitation concentration degree in the $i$ th year, and the range of values is from 0 to 1. If total precipitation occurs on a specific day (pentad or month), the maximum value (1) of $P C D_{i}$ can be obtained. If total precipitation is evenly distributed, the figure can reach its minimum value (0). $P C P_{i}$ represents the period (day, pentad or month) in which the total precipitation of the research period in the $i$ th year occurs. Detailed calculating methods and theories can be found in a paper written by Yesilirmak and Atatanir [23].

Analysis of diurnal variation is composed of precipitation, precipitation frequency and precipitation intensity hour by hour. The precipitation and the precipitation frequency for one hour are the respective sums of precipitation and number of precipitation occurrences over this hour per day during the research period, and the precipitation intensity for one hour is the ratio of precipitation and precipitation frequency corresponding to this hour.

\section{Results and Discussion}

\subsection{Inter-Annual Fluctuation}

According to the results from 2009 to 2015, in-situ observed annual precipitation and its inter-annual variations at meteorological stations (PG-4164-PG-3446) differ from the Tuole weather station (WS-3367), some are even dramatically opposite (Figure 2). Among them, annual precipitation of PG-3446 was always the lowest, with an average of $224.9 \mathrm{~mm}$. Temporal analysis of the annual 
precipitation of PG-4164, PG-3915 and WS-3367 suggested that a change in magnitude was following a sharply increasing trend, and their annual average precipitation values were $377.5 \mathrm{~mm}, 367.0 \mathrm{~mm}$, and $355.8 \mathrm{~mm}$, respectively. In terms of inter-annual fluctuations, a clear majority of $P a$ (from $-14.9 \%$ to $12.7 \%)$ fell within normal levels, and less $(-35.7 \%, 2013)$ or more $(39.3 \%, 2015)$ only occurred once in PG-3446 (Figure 2). Similarly, the coefficient of variation (Cv) did not exceed 0.10, except for PG-3446 (0.22), which was on the high side. Using a monthly scale, the inter-annual fluctuation of precipitation increased substantially, but the distribution of $\mathrm{Cv}$ showed significant differences (Figure 3). Generally speaking, the $\mathrm{Cv}$ was above 0.8 when monthly precipitation was lower than $20 \mathrm{~mm}$. Conversely, the $\mathrm{Cv}$ was basically stable at about 0.4 . Furthermore, the relationship between the $\mathrm{Cv}$ and average monthly precipitation can be described by a power function equation (statistically significant at the $99 \%$ confidence level), and it was applicable whether or not the elevation was consistent (Figure 3). Thus, generally or individually, the annual precipitation figures were basically stable, and the inter-annual variability was occasionally somewhat larger at low altitude zones with low precipitation. With a decrease in the time scale, the inter-annual fluctuation of precipitation increased clearly, but its variability showed a spatial-temporal distribution characteristic of being highly negative that correlated with precipitation.

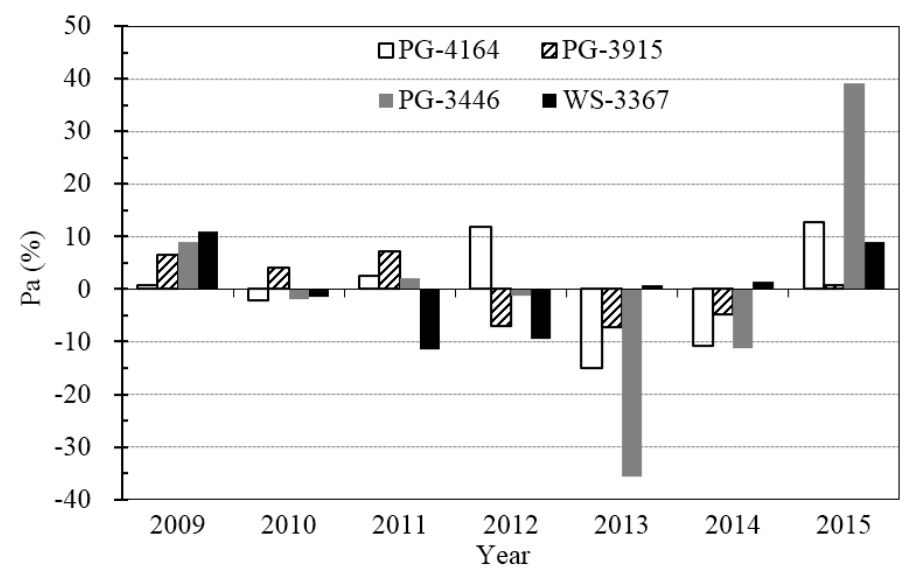

Figure 2. Pa of annual precipitation from 2009 to 2015.

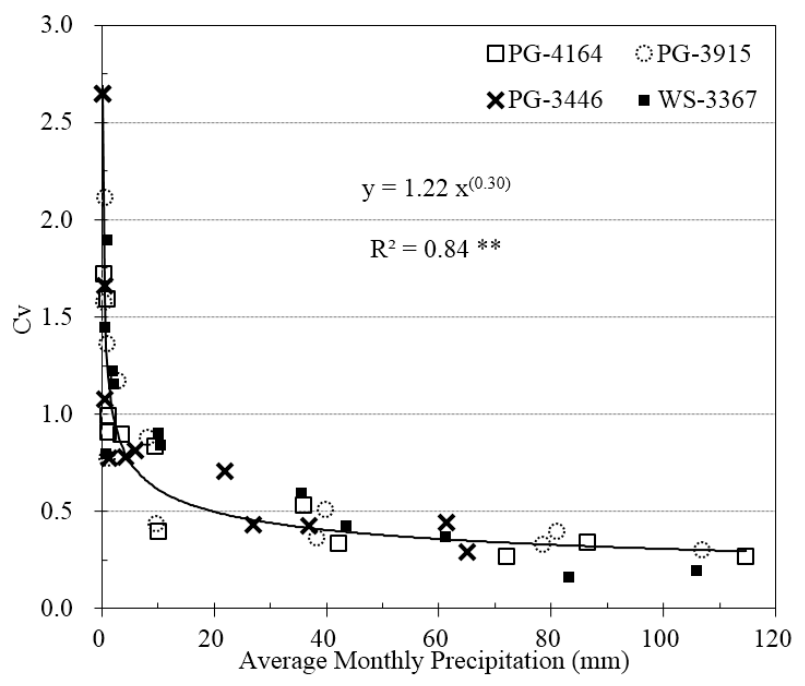

Figure 3. Correlation between $\mathrm{Cv}$ and average monthly precipitation during 2009-2015. The trend line was derived from data from all four sites, whereas that of the single site is not shown. The superscript ${ }^{\prime * * \prime}$ indicates statistical significance at the $99 \%$ confidence level. 
The inter-annual distribution characteristics of precipitation at lower altitudes of the Qinghai-Tibetan Plateau have been widely discussed. According to precipitation data of 56 meteorological stations from 1961 to 2000, the anomaly percentages of annual precipitation in the southern region were generally less than $20 \%$, while those of the northern region were less than $15 \%$ [24]. A similar conclusion was also found in related research on precipitation in the flood season [25]. On a seasonal scale, the inter-annual variability of precipitation was usually the lowest in summer, followed by spring and autumn, while winter showed maximum inter-annual variability [26]. As for the upper reaches of the Shule River, based on the observation data of the Tuole weather station for more than 50 years, annual precipitation was significantly increased in the area below $3000 \mathrm{~m}$, but no change was found in areas where the elevation exceeded $3000 \mathrm{~m}$ [27]. These results show that the inter-annual fluctuations of precipitation in the Qinghai-Tibetan Plateau were generally weaker, and the negative correlation in the variation rate and precipitation is still applicable in the alpine region. This is most likely caused by the combined effects of the atmospheric circulation, the geographical environment, the hydrological cycle and other factors. Firstly, during the rainy season, the Qinghai-Tibetan Plateau is mainly controlled by the southeast monsoon, the southwest monsoon and the westerlies, and the influential extents of these three atmospheric circulation systems interact in the Hexi inland region, where a regulatory mechanism of trading off and taking turns often occurs. Secondly, the Tibetan Plateau is secluded and inland, and the terrain is on the high side, so the variation characteristics of warm and humid air may be greatly weakened due to the long journey as well as by the barrier layers of mountains. Finally, which is perhaps the most noteworthy point, the precipitation recycling is likely to play an important role in the formation mechanism of mountain precipitation [28]. During the daytime, strong evapotranspiration leads to considerable water loss (measured over the same period), while plunging temperatures at night force water vapor to rapidly cool and even condense; therefore, this area is prone to small precipitation events. This is particularly evident in high mountainous areas, which have higher soil moisture and a greater temperature diurnal range [29], and should be the key to the inter-annual variability of precipitation, which is usually larger in the low elevation areas with opposite conditions.

\subsection{Annual Distribution}

As shown in Figure 4, the distribution of monthly precipitation has distinct wet and dry seasons, and the annual characteristics of the four sites are very similar from the proportion point of view. During the period from May to September, the precipitation is relatively abundant, reaching as much as $85.6-98.5 \%$ of the annual precipitation, and the monthly precipitation is generally above $30 \mathrm{~mm}$. The maximum monthly precipitation occurs mainly in July $(67.9 \%)$ followed by June (28.6\%); the sum of the two accounted for 42.6-65.1\% of the annual precipitation during 2009-2015. In contrast, the precipitation over the remaining months is very scarce; most of the monthly precipitation is less than $10 \mathrm{~mm}$, sometimes even as low as $0 \mathrm{~mm}$. For a more objective evaluation of the uneven distribution of precipitation, Tables 2 and 3 list the results of yearly $P C D$ and $P C P$ respectively, based on pentad precipitation. In the last seven years, values of $P C D$ were above 0.71 , with a maximum up to 0.83 , and regional (non-significant difference at the $95 \%$ confidence level) and inter-annual differences were not obvious (Table 2). The PCP was also relatively stable, ranging from $180.9^{\circ}$ to $197.8^{\circ}$, and occurring in the 37th-41st pentads (Table 3). Therefore, the annual distribution is highly uneven and has no visible vertical differentiation, with the highest probability period of heavy precipitation events occurring in early and mid-July.

Table 2. Inter-annual and regional variation of PCD during 2009-2015.

\begin{tabular}{ccccccccc}
\hline Site & $\mathbf{2 0 0 9}$ & $\mathbf{2 0 1 0}$ & $\mathbf{2 0 1 1}$ & $\mathbf{2 0 1 2}$ & $\mathbf{2 0 1 3}$ & $\mathbf{2 0 1 4}$ & $\mathbf{2 0 1 5}$ & Average \\
\hline PG-4164 & 0.77 & 0.75 & 0.78 & 0.81 & 0.77 & 0.73 & 0.75 & $\mathbf{0 . 7 7}$ \\
PG-3915 & 0.77 & 0.77 & 0.80 & 0.80 & 0.79 & 0.75 & 0.75 & $\mathbf{0 . 7 8}$ \\
PG-3446 & 0.75 & 0.71 & 0.82 & 0.83 & 0.79 & 0.79 & 0.79 & $\mathbf{0 . 7 8}$ \\
WS-3367 & 0.73 & 0.75 & 0.77 & 0.83 & 0.80 & 0.73 & 0.73 & $\mathbf{0 . 7 6}$ \\
\hline
\end{tabular}


Table 3. As in Table 2, but for PCP (unit: degree in direction).

\begin{tabular}{ccccccccc}
\hline Site & $\mathbf{2 0 0 9}$ & $\mathbf{2 0 1 0}$ & $\mathbf{2 0 1 1}$ & $\mathbf{2 0 1 2}$ & $\mathbf{2 0 1 3}$ & $\mathbf{2 0 1 4}$ & $\mathbf{2 0 1 5}$ & Average \\
\hline PG-4164 & 191.9 & 183.8 & 182.7 & 185.5 & 189.1 & 191.2 & 193.0 & $\mathbf{1 8 8 . 2}$ \\
PG-3915 & 197.8 & 180.9 & 193.7 & 188.0 & 190.7 & 194.5 & 182.7 & $\mathbf{1 8 9 . 8}$ \\
PG-3446 & 193.8 & 183.0 & 183.6 & 182.2 & 182.3 & 182.9 & 185.6 & $\mathbf{1 8 4 . 8}$ \\
WS-3367 & 191.9 & 187.8 & 191.1 & 182.3 & 181.5 & 196.7 & 183.8 & $\mathbf{1 8 7 . 9}$ \\
\hline
\end{tabular}

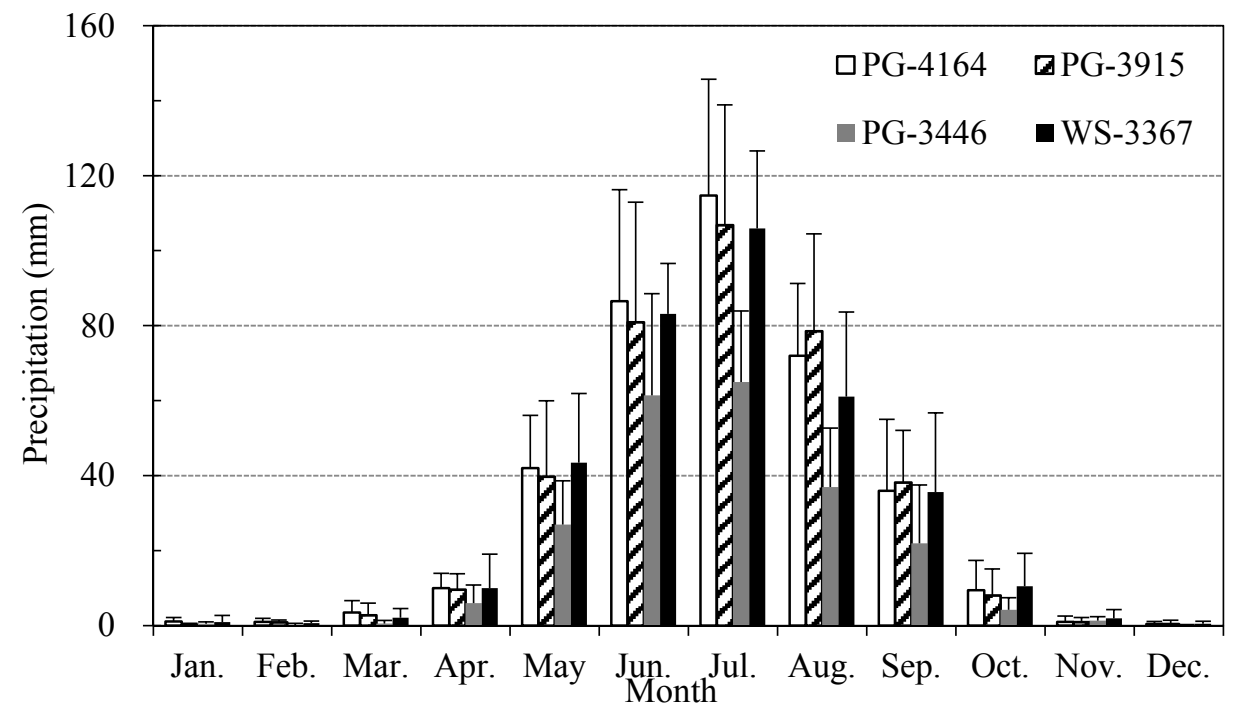

Figure 4. Distribution of average monthly precipitation during 2009-2015. Error bars represent one standard deviation.

In the Qinghai-Tibetan Plateau, distinct wet and dry seasons are the strongest indicators of an uneven annual distribution of precipitation. In general, precipitation increases sharply from May, gradually advancing to the northwest from the southeastern part of the plateau. Around June, the whole plateau appears to experience the rainy season, and this continues until the end of summer. After September, precipitation decreases dramatically, with the plateau switches to the dry season starting from the West, spreading East. Most of the Qinghai-Tibetan Plateau is therefore dominated by summer precipitation. According to the daily precipitation measurements from 1967 to 2008 recorded at 68 meteorological stations, Yang et al. [30] found that $P C D$ values of the Qinghai-Tibet Plateau are basically between 0.4 and 0.8 , while $P C P$ is mainly within the 36th-41st pentads. The Qilian mountains are located in the relatively rainy zone of the Qinghai-Tibetan Plateau, and the summer (from June to August) precipitation is generally more than sixty percent of the annual precipitation, while the proportion of wet season (from May to September) precipitation accounts for as high as about $90 \%$ [31]. These results are consistent with our observations, indicating the vertical change of precipitation distribution during the year is not apparent. As for the great contrast between the wet and dry season, it is most likely to be closely related to the thermal difference. On the one hand, the thermal difference between land and sea has a seasonal variation, with the wind direction of monsoons and the volume of warm, moist air carried by them being bound to change [32]. On the other hand, affected by the thermal difference between the plateau and surrounding atmosphere at the same height, the ground layer in summer is a thermal low and exhibits a prevailing cyclonic circulation, and in winter it is just the opposite [33]. The two are intertwined and coupled with the seasonal variation of evapotranspiration and the forcing of the plateau terrain; this results in precipitation in most parts of the Tibetan Plateau that are concentrated before and after the summer. 


\subsection{Diurnal Variation}

Considering the low proportion of solid precipitation, the accuracy of the data and other factors, the analysis on diurnal variation of precipitation only uses the rainy season (from 23 May to 6 September) in 2013, which has a similar result and no significant snowfall event, as an example. During this period, the total precipitation accounts for about eighty percent of the annual precipitation. As can be seen from the distribution of hourly precipitation (Figure 5), the characteristic of diurnal variation is very distinct, with the minimum value located at 1100 or 1200 Local Standard Time (LST), and the maximum value appearing in the 1600-1900 LST. In addition, for convenience of the following analysis, the precipitation rates hour by hour of three sites are divided into high precipitation and low precipitation according to whether or not they are higher than their respective averages (RG-4031: $14.5 \mathrm{~mm}$; RG-3915: $11.6 \mathrm{~mm}$; RG-3726: $6.6 \mathrm{~mm}$ ). After this processing, it can be found that the precipitation of the three sites showed great differences, but the concentrated hours $(0400$, 0600-1400 LST) of low precipitation were uniform, and differed (RG-4031: 0200, 0500 LST; RG-3915: 0300, 2300 LST; RG-3726: 0300, 0500 LST) only individually. In addition, the proportion (RG-4031: 24.8\%; RG-3915: 23.8\%; RG-3726: 15.3\%) of low precipitation accounted for in the total precipitation displayed a continuously declining trend with a decrease in altitude. For an in-depth understanding of this phenomenon, the diurnal variation of precipitation frequency and precipitation intensity was further analyzed using the same method, and the results were broadly similar. Among them, the most unexpected is that the vertical change trends of the two are very different. During the corresponding hours of their respective low precipitation for above three sites, the proportion of precipitation frequency increased with the decline of elevation, which accounts for $36.8 \%, 40.2 \%$ and $55.3 \%$ of the total number over a duration of $24 \mathrm{~h}$ (Table 4 ). The precipitation intensity was just the opposite, i.e., about $0.69,0.60$ and 0.24 times of the average throughout the day (Table 4). The above results indicate that the alpine precipitation occurred mainly in the afternoon to midnight (1500-0100 LST), and this characteristic would become more and more obvious with a decrease in altitude. Nevertheless, the causes are not consistent; the higher altitude areas were mainly dominated by the precipitation frequency, while the lower altitude region usually depended on the precipitation intensity.

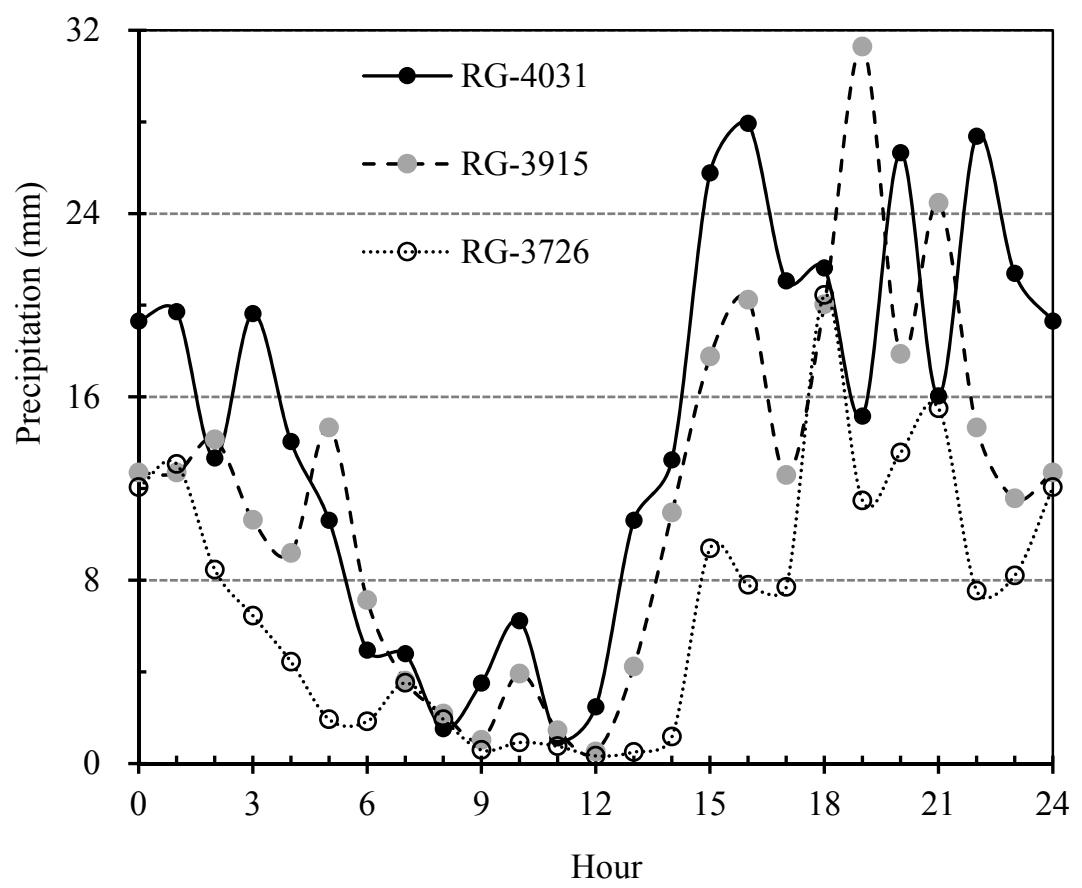

Figure 5. Diurnal variation of precipitation in the rainy season of 2013. 
Table 4. Results of precipitation frequency and precipitation intensity in the rainy season of 2013.

\begin{tabular}{ccccccc}
\hline \multirow{2}{*}{ Site } & \multicolumn{3}{c}{ Precipitation Frequency } & \multicolumn{3}{c}{ Precipitation Intensity $(\mathbf{m m} / \mathbf{h})$} \\
\cline { 2 - 7 } & $\mathbf{H}_{\mathbf{2 4}}$ & $\mathbf{H}_{\mathbf{L P}}$ & $\mathbf{H}_{\mathbf{L P}} / \mathbf{H}_{\mathbf{2 4}}$ & $\mathbf{H}_{\mathbf{2 4}}$ & $\mathbf{H}_{\mathbf{L P}}$ & $\mathbf{H}_{\mathbf{L P}} / \mathbf{H}_{\mathbf{2 4}}$ \\
\hline RG-4031 & 563 & 207 & $\mathbf{3 6 . 8} \%$ & 0.58 & 0.40 & $\mathbf{6 8 . 9 \%}$ \\
RG-3915 & 410 & 165 & $\mathbf{4 0 . 2} \%$ & 0.63 & 0.38 & $\mathbf{6 0 . 0} \%$ \\
RG-3726 & 284 & 157 & $\mathbf{5 5 . 3} \%$ & 0.63 & 0.15 & $\mathbf{2 4 . 2 \%}$ \\
\hline
\end{tabular}

Note: $\mathrm{H}_{24}$ is the sum (average) of precipitation frequency (precipitation intensity) for all $24 \mathrm{~h} . \mathrm{H}_{\mathrm{LP}}$ is the sum (average) of precipitation frequency (precipitation intensity) for hours of low precipitation.

The diurnal variation of precipitation is generally an atmosphere thermodynamic response to the alternation of day and night solar radiation, and the peak that occurred in the afternoon is a typical feature of continental diurnal variation [34]. According to TRMM 3B42 data during 1998-2008, summer rainfall exhibited marked diurnal variation over most of the land in the Asian monsoon region, and the peak in Eastern China and the north-central part of the Qinghai-Tibet Plateau occurred mainly from 1500 to 1800 LST [35]. Similar results are obtained from the precipitation data of meteorological stations in China from 1991 to 2004, which found the Qinghai-Tibet Plateau rainfall peak occurred around midnight, and the phenomenon of a single peak in the morning or a double peak in the morning as well as afternoon also exists [36]. Moreover, studies on the rainfall duration and the phase of the diurnal variation reveal that the long-duration rainfall events (an event that lasts longer than $6 \mathrm{~h}$ ) have their maximum around early morning, while short-duration rainfall events (an event of 1-6 h in duration) reach their peaks around late afternoon [37]. These findings are consistent with our observed results. Thus, besides differences in horizontal direction, the diurnal variation of precipitation also has a vertical change in high mountain areas [38]. As is known, atmospheric circulation and convection activity play an important role in the formation process of precipitation, and the intensity gradually increases with the temperature rise after sunrise. By mid-afternoon, when sufficient water vapor is encountered, cumulonimbus clouds may form in large quantities, and this may trigger precipitation events. After sunset, the air temperature drops abruptly, the convective activity rapidly weakens and precipitation sharply decreases. The vertical differences are likely to be derived from the diversity of the precipitation mechanism in mountainous areas, which makes the influence of convective precipitation in different altitude zones inconsistent [39]. At high elevations, the mountain peaks rising one after another can block water vapor, and the hydrothermal conditions including the diurnal temperature range, actual evapotranspiration, etc. develop in a direction conducive to mutual transformation of water between the soil and the atmosphere. Thus, frequent occurrence of small precipitation events (especially in the early morning) effectively weaken the degree of concentration of diurnal distribution. Because of the unfavorable accumulation and condensation of water vapor, precipitation events in low elevations almost completely depend on convective activity. Therefore, the diurnal variation of alpine precipitation is increasingly concentrated the more the altitude decreases. Meanwhile, the dominant factor is gradually transformed from precipitation frequency into precipitation intensity.

\section{Conclusions}

Through comparative analysis using field observation data from the upper Shule River basin $(3400-4200 \mathrm{~m})$ and daily precipitation records of Tuole station during 2009-2015, this paper preliminarily revealed the distribution characteristics of alpine precipitation on the main time scale as well as their vertical differentiation, and showed some findings which cannot be reflected from data of the surrounding weather stations. The major results are summarized as follows:

(i) The annual precipitation was generally stable, with inter-annual variability that was only somewhat larger at low altitude zones for individual years; the inter-annual fluctuation of monthly precipitation increased substantially, but the variability showed marked spatial-temporal distribution that decreased with increased precipitation. Based on several years of in-situ observational data, the basic characteristics of alpine precipitation should be able to be objectively reflected, and the 
applicability of the related conclusions is extensive. Of course, to obtain greater representative research results, especially in low altitude areas and for study phases where the rainfall is noticeably lower, a longer sequence of years is indispensable for the area.

(ii) The annual distribution is highly uneven, most of the precipitation is concentrated in May to September, and there is no significant regional or inter-annual change. An ideal and reliable way to determine the key period of precipitation for an ungauged mountainous area is by analyzing existing data from surrounding stations.

(iii) The diurnal variation of precipitation was pronounced, mainly occurring from afternoon to midnight (1500-0100 LST), and presented a notable vertical difference dominated by precipitation intensity or precipitation frequency. Rapid turnover of local water should play an important role in the formation of precipitation and hydrological cycles in high mountainous areas. As global warming continues, whether the response level and potential impact of this part of the water cycle are more significant has yet to be further explored. It is also a key link for constructing an integrative water management system at the catchment scale to guarantee the sustainable development and ecological security of inland river basin.

In conclusion, although the basic features are consistent, the vertical differentiation of alpine precipitation temporal distribution is also worthy of attention, and the diversity of the precipitation mechanism are likely to be the root causes of these variations. At this stage, the field observation of alpine precipitation has great worth and needs to be strengthened urgently.

Acknowledgments: This study was financed by the National Key Basic Research Program of China (973 Program) (No. 2013CBA01806), the National Natural Science Foundation of China (No. 41130638; No. 41501076) and the Natural Science Foundation of Gansu Province (No. 1606RJZA104). The authors would like to thank the Editors and the reviewers for their crucial comments that improved the quality of this paper.

Author Contributions: Qingfeng Li performed data collection, result calculation and analysis, and wrote the article. Guojing Yang contributed to the article's discussion and made suggestions based on the study's goals.

Conflicts of Interest: The authors declare no conflict of interest.

\section{References}

1. Allan, R.P.; Soden, B.J. Atmospheric warming and the amplification of precipitation extremes. Science 2008, 321, 1481-1484. [CrossRef] [PubMed]

2. Terzago, S.; Cassardo, C.; Cremonini, R.; Fratianni, S. Snow Precipitation and Snow Cover Climatic Variability for the Period 1971-2009 in the Southwestern Italian Alps: The 2008-2009 Snow Season Case Study. Water 2010, 2, 773-787. [CrossRef]

3. Bala, G.; Caldeira, K.; Nemani, R.; Cao, L.; Ban-Weiss, G.; Shin, H.J. Albedo enhancement of marine clouds to counteract global warming: Impacts on the hydrological cycle. Clim. Dynam. 2011, 37, 915-931. [CrossRef]

4. Coppola, E.; Verdecchia, M.; Giorgi, F.; Colaiuda, V.; Tomassetti, B.; Lombardi, A. Changing hydrological conditions in the Po basin under global warming. Sci. Total Environ. 2014, 493, 1183-1196. [CrossRef] [PubMed]

5. Wang, Z.; Deng, X.Z.; Song, W.; Li, Z.H.; Chen, J.C. What is the main cause of grassland degradation? A case study of grassland ecosystem service in the middle-south Inner Mongolia. Catena 2017, 150, 100-107. [CrossRef]

6. Davis, J.; Pavlova, A.; Thompson, R.; Sunnucks, P. Evolutionary refugia and ecological refuges: Key concepts for conserving Australian arid zone freshwater biodiversity under climate change. Glob. Chang. Biol. 2013, 19, 1970-1984. [CrossRef] [PubMed]

7. Son, K.H.; Bae, D.H. Drought analysis according to shifting of climate zones to arid climate zone over Asia monsoon region. J. Hydrol. 2015, 529, 1021-1029. [CrossRef]

8. Banihabib, M.E.; Hasani, K.; Bavani, A.R.M.; Asgari, K. A framework for the assessment of reservoir operation adaptation to climate change in an arid region. Int. J. Glob. Warm. 2016, 9, 286-305. [CrossRef]

9. Yin, Z.L.; Feng, Q.; Zou, S.B.; Yang, L.S. Assessing Variation in Water Balance Components in Mountainous Inland River Basin Experiencing Climate Change. Water 2016, 8, 472. [CrossRef] 
10. Deng, X.Z.; Zhao, C.H. Identification of Water Scarcity and Providing Solutions for Adapting to Climate Changes in the Heihe River Basin of China. Adv. Meteorol. 2015. [CrossRef]

11. Shinohara, Y.; Kumagai, T.; Otsuki, K.; Kume, A.; Wada, N. Impact of climate change on runoff from a mid-latitude mountainous catchment in central Japan. Hydrol. Process. 2009, 23, 1418-1429. [CrossRef]

12. Smith, P.C.; Calanca, P.; Fuhrer, J. A Simple Scheme for Modeling Irrigation Water Requirements at the Regional Scale Applied to an Alpine River Catchment. Water 2012, 4, 869-886. [CrossRef]

13. Deng, X.Z.; Gibson, J.; Wang, P. Quantitative measurements of the interaction between net primary productivity and livestock production in Qinghai Province based on data fusion technique. J. Clean Prod. 2017, 142, 758-766. [CrossRef]

14. Kunz, M. Characteristics of large-scale orographic precipitation in a linear perspective. J. Hydrometeorol. 2011, 12, 27-44. [CrossRef]

15. Hoover, J.D.; Doesken, N.; Elder, K.; Laituri, M.; Liston, G.E. Temporal trend analyses of alpine data using North American regional reanalysis and In Situ data: Temperature, wind Speed, precipitation, and derived blowing snow. J. Appl. Meteorol. Clim. 2014, 53, 676-693. [CrossRef]

16. Tong, K.; Su, F.G.; Yang, D.Q.; Hao, Z.C. Evaluation of satellite precipitation retrievals and their potential utilities in hydrologic modeling over the Tibetan Plateau. J. Hydrol. 2014, 519, 423-437. [CrossRef]

17. Saghafian, B.; Bondarabadi, S.R. Validity of regional rainfall spatial distribution methods in mountainous areas. J. Hydrol. Eng. 2008, 13, 531-540. [CrossRef]

18. Buytaert, W.; Celleri, R.; Willems, P.; De Bievre, B.; Wyseure, G. Spatial and Temporal Rainfall Variability in Mountainous Areas: A Case Study from the South Ecuadorian Andes. J. Hydrol. 2006, 329, 413-421. [CrossRef]

19. Yang, M.X.; Yao, T.D.; Gou, X.H.; Wang, H.J.; Ha, L.S. Comparison analysis of the summer monsoon precipitation between northern and southern slopes of Tanggula Mountains, Qinghai-Xizang (Tibetan) Plateau: A case study in summer 1998. Hydrol. Process. 2007, 21, 1841-1847. [CrossRef]

20. Chen, S.Y.; Liu, W.J.; Qin, X.; Liu, Y.S.; Zhang, T.Z.; Chen, K.L.; Hu, F.Z.; Ren, J.W.; Qin, D.H. Response characteristics of vegetation and soil environment to permafrost degradation in the upstream regions of the Shule River Basin. Environ. Res. Lett. 2012, 7, 045406. [CrossRef]

21. Luo, K.S.; Tao, F.L.; Deng, X.Z.; Moiwo, J.P. Changes in potential evapotranspiration and surface runoff in 1981-2010 and the driving factors in Upper Heihe River Basin in Northwest China. Hydrol. Process. 2017, 31, 90-103. [CrossRef]

22. Deng, X.Z.; Singh, R.B.; Liu, J.G.; Guneralp, B. Water productivity and integrated water resources management. Phys. Chem. Earth 2016, 96, 1. [CrossRef]

23. Yesilirmak, E.; Atatanir, L. Spatiotemporal variability of precipitation concentration in western Turkey. Nat. Hazards 2016, 81, 687-704. [CrossRef]

24. Zhang, L.; Miao, Q.L. Precipitation changes in the Tibetan Plateau during the last four decades. Arid Land Geogr. 2007, 30, 240-246.

25. Zhou, S.W.; Wang, Q.H.; Du, J.; Ma, Z.F. Characteristics of spatial and temporal distribution of precipitation in flood season over the Tibetan Plateau. Clim. Environ. Res. 2011, 16, 723-732. (In Chinese).

26. Lin, H.B.; You, Q.L.; Jiao, Y.; Min, J.Z. Spatial and temporal characteristics of the precipitation over the Tibetan Plateau from 1961 to 2010 based on high resolution grid-observation dataset. J. Nat. Resour. 2015, 30, 271-281.

27. Lan, Y.C.; Hu, X.L.; Xiao, S.C.; Wen, J.; Wang, G.Y.; Zou, S.B.; La, C.F.; Song, J. Study on climate change in mountainous region of Shulehe River Basin in past 50 years and its effect to mountainous runoff. Plateau Meteorol. 2012, 31, 1636-1644. (In Chinese).

28. Hua, L.J.; Zhong, L.H.; Ke, Z.J. Characteristics of the precipitation recycling ratio and its relationship with regional precipitation in China. Theor. Appl. Climatol. 2017, 127, 513-531. [CrossRef]

29. Hua, L.J.; Zhong, L.H.; Ke, Z.J. Precipitation recycling and soil-precipitation interaction across the arid and semi-arid regions of China. Int. J. Climatol. 2016, 36, 3708-3722. [CrossRef]

30. Yang, W.; He, J.H.; Wang, P.X.; Wang, C.H. Inhomogeneity characteristics of intra-annual precipitation over the Tibetan Plateau in recent 42 years. Acta Geogr. Sin. 2011, 66, 376-384.

31. Meng, X.J.; Zhang, S.F.; Zhang, Y.Y.; Wang, C.C. Temporal and spatial changes of temperature and precipitation in Hexi Corridor during 1955-2011. J. Geogr. Sci. 2013, 23, 653-667. [CrossRef] 
32. Xu, X.D.; Zhao, T.L.; Lu, C.G.; Shi, X.H. Characteristics of the water cycle in the atmosphere over the Tibetan Plateau. Acta Meteorol. Sin. 2014, 72, 1079-1095.

33. Zhou, S.W.; Wu, P.; Wang, C.H.; Han, J.C. Spatial distribution of atmospheric water vapor and its relationship with precipitation in summer over the Tibetan Plateau. J. Geogr. Sci. 2012, 22, 795-809. [CrossRef]

34. Tanaka, L.M.D.S.; Satyamurty, P.; Machado, L.A.T. Diurnal variation of precipitation in central Amazon Basin. Int. J. Climatol. 2014, 34, 3574-3584. [CrossRef]

35. Mao, J.Y.; Wu, G.X. Diurnal variations of summer precipitation over the Asian monsoon region as revealed by TRMM satellite data. Sci. China Earth Sci. 2012, 55, 554-566. [CrossRef]

36. Yu, R.C.; Zhou, T.J.; Xiong, A.Y.; Zhu, Y.J.; Li, J.M. Diurnal variations of summer precipitation over contiguous China. Geophys. Res. Lett. 2007, 34, L01704. [CrossRef]

37. Yu, R.C.; Yuan, W.H.; Li, J.; Fu, Y.F. Diurnal phase of late-night against late-afternoon of stratiform and convective precipitation in summer southern contiguous China. Clim. Dynam. 2010, 35, 567-576. [CrossRef]

38. Mandapaka, P.V.; Germann, U.; Panziera, L. Diurnal cycle of precipitation over complex Alpine orography: Inferences from high-resolution radar observations. Q. J. R. Meteorol. Soc. 2013, 139, 1025-1046. [CrossRef]

39. Long, Q.C.; Chen, Q.L.; Gui, K.; Zhang, Y. A Case Study of a Heavy Rain over the Southeastern Tibetan Plateau. Atmosphere 2016, 7, 118. [CrossRef]

(C) 2017 by the authors. Licensee MDPI, Basel, Switzerland. This article is an open access article distributed under the terms and conditions of the Creative Commons Attribution (CC BY) license (http:/ / creativecommons.org/licenses/by/4.0/). 